\title{
Teenage Pregnancy in Malaysia: Understanding the Importance of Social Support in Relation to Coping, Resilience and Mental Health
}

\author{
Saim, N.J., Ghazinour, M., Richter, J.
}

\begin{abstract}
Losing the social support from family and friends may affect coping, resilience and increase a risk of mental health problems among pregnant teenagers and teenage mothers. This article aims to describe the importance and availability of social support related to coping, resilience and mental health among unwed pregnant teenagers and teenage mothers in Malaysia during their stay in a shelter home. A purposive sampling was employed to select seventeen respondents from 128 unmarried pregnant and teenage mothers; age 10 to 18 years living in four different shelter homes owing that they were pregnancy out of wedlock. The findings are based on analysis of interviews and questionnaires related to social support, ways of coping, resilience and mental health. The study found strong indication in both, the qualitative and quantitative data, that unwed pregnant teenagers and teenage mothers have poor social support in terms of availability and adequacy. Hence, it reflected in their ways of coping, resilience, and put them at risk to develop mental health problems if untreated. The authorities and the staff in shelter homes are advice to take seriously social support aspects, especially from the family since they play a vital role for well-being and mental health of unwed pregnant teenagers and teenage mothers.
\end{abstract}

Index Terms: Teenage pregnancy, unwed mothers, social support, Malaysia.

\section{INTRODUCTION}

It is estimated that about 16 million teenagers become mothers every year and account for more than 30 births per minute worldwide [1]. We opted for the definition of teenage pregnancy by the United Nations Children's Fund [2], which defined teenage pregnancy as a pregnancy among teenagers aged between 13-19 years and also refers to teenagers who have not reached legal adulthood. According to the statistic from the Police Department Royal Malaysia on statutory rape of victims of 16 years or younger; 2049 cases were reported in 2009 and 2419 cases in 2011 [3]. In Malaysia, pregnancy out of wedlock happened in about one third of pregnancies among teenagers [4]. As a comparison, Kashiwase [5] reported that more than four fifths among first births of teen mothers were conceived out of wedlock in Japan.

Teenage pregnancies are commonly associated with sexual risk behavior, multiple partners, substance abuse [6] or sexual abuse [7]. It also became an issue of concern owing that pregnancy among teenagers could endanger their emotional status; such as emerging depressive symptoms and

Revised Manuscript Received on September 25, 2019

Saim, Nor Jana, School of Psychology and Human Well Being, Universiti Kebangsaan Malaysia, Bangi, Malaysia.

Ghazinour, Mehdi, Police Education Unit, Umeå University, Umeå, Sweden.

Richter, Jörg. School of Life Sciences, Faculty of Health Sciences, University of Hull, Kingston upon Hull, United Kingdom. social problems e.g. educational disruption [8], [9]; and increases the risk of medical complications such as anemia and postpartum complications [10], [11], [12]. Furthermore, unwed teenage pregnancy is not in agreement with Asian norms [13], [14], [15], [16], [17], religious beliefs [18], [19] and can lead to heinous crime; infanticide [20].

In Malaysia, a spur-of-the-moment marriage often happens if a girl is pregnant out of wedlock. Other alternatives are to undergo an abortion; which is illegal unless for medical purposes [21], or that parents send their daughter to a shelter home for a certain period mainly to hide the pregnancy [17]. Teenagers below 18 years are encouraged to choose governmental shelter homes. But, their families usually are free to choose either a governmental or non-governmental shelter home [17]. Although the Malaysian society and authority are concerned on this matter, however, people rarely talk about this topic in public due to shame and stigma [2]. In general, staying in a shelter home might be beneficial for the residents in the sense of having a shelter when they have no place to stay and make progress in their psychosocial functions [22]. However, the voices of the residents, especially of young people are often unheard [23], [24]. It can be a difficult experience and challenge to maintain strength and well-being for these young, pregnant women, and often includes a loss of their usual social support.

Social Support, Coping Behavior, Resilience and a Risk of Mental Health Problems among Unwed Teenage Mothers

Social support is defined as availability of resources to the individual especially during a crisis. Three entities of social support are tangible, appraisal and emotional support [25]. The main resources of social support for teenagers are family and friends [26], [27]. Several studies demonstrated that social support moderates the effects of stress on psychological well-being [28]. Social support is not an independent factor associated with mental health, but it could strengthen the internal resources or/and diminish stress [29]. The absence or lack of social support could lead to psychological disturbance such as emotional loneliness or social loneliness [30], [31]; mental health problems such as bipolar depression [32], and maternal depressive symptoms [33], [34].

Studies on social support and coping concluded that receiving social

support will facilitate coping and assist a person to deal with 
stressors [30], [35]. The social support that continuously is available helps a person to identify and to gather their coping resources, hence may improve their coping [35]. Coping is defined as realistic and flexible thoughts and acts that solve problems and thereby will reduce stress [36]. According to Folkman and Lazarus [37], coping is a process that involve observations and assessment to a condition that a person need to cope. Thus, coping is a shifting and changing process through continuous appraisals and reappraisals depending on the person-environment relationship [37]. There are two different types of coping. Problem-focused coping purposely is applied to manage or alter the problem that causes distress, for example, generating alternative solutions, weighting the alternatives depending on cost and benefits either directed at the environment or directed at the self. Emotion-focused coping such as avoidance, minimization, distancing and, selective attention refers to coping that leads to coordinate emotional responses to the situation they encounter [37]. Thoits [38] stressed that social support works as coping assistance, and it has common functions as coping; for example, problem-focused coping and tangible social support are aimed at changing and managing the situation, whilst emotion-focused coping and emotional support purposely to ameliorate the feelings.

Panzarine [39] noted that anticipation coping prior to birth was among the contributing factors to a relatively smooth transition from adolescence to motherhood, but those teenage mothers who showed depressive symptoms commonly used emotion-focused coping more often compared to non-depressed individuals [40]. Research on coping among pregnant women from multiple backgrounds in the United States found that pregnant women commonly employed spiritual coping, one emotion-focused way of coping, most often in early and mid-pregnancy owing their concern on unpredictable issues at miscarriage [41]. Avoidant coping was least often applied, especially during late term of pregnancy, and it was predicted by severe anxiety [41].

Generally, teen mothers perceived interpersonal factors such as support from their partner is important for their emotional well-being [42]. Emotional support such as sense of belonging and attachment are important factors representing environmental aspects that could influence the resilience of young people [43], [44]. The teenagers also normally emphasized the importance of acceptance from the people around them in order to be resilient [45]. There are various definitions of resilience (e.g. [46], [47]. Barnad [48] defined resilience as individual characteristics, which are associated with healthy development and life success, also called internal assets or personal competencies. However, resilience is not only an individual trait but, derives from the interaction process between the individual and its environment [49], [44]. According to Ungar's [50] ecological model, resilience is defined as the ability to rebound from stressful, adversity or negative life events. Resilience among teenagers could be described as the dynamic attribute between their environment and the adaption of a person in the situation that they are facing [51], [52].

It is important to focus on resilience among teen mothers in Malaysia as a study of resilience among 489 female trainees of the Malaysian National Service Training Program which were selected randomly among 18-year-old Malaysian teenagers found that about $45 \%$ of them were non-resilient [51]. Abdullah [51] defined resilience as the process, capacity or outcome when one successfully adapt in challenging circumstances. Being resilient means that one is capable of bouncing back from being defeated and disappointments; turning losses into learning experiences and coping with stressful and difficult life events [51]. Resilience is particularly important for the well-being of those who are considered as delinquent, deviant and disordered teenagers [45].

In the situation of unwed teenage mothers, most of them getting pregnant without planning; they are unprepared for motherhood; they experience an academic disruption; they are often left by their babies' fathers (usually their boyfriend); they are confronted with family conflicts due to the pregnancy; they are sent to a shelter home by their families; and they experience a strong stigma from society - all these conditions might cause or contribute to the development of mental health problems. Geller [53] called these stressful circumstances stressful life events. The classic assumptions for a person in such a possibly depression-prone situation are that they lose their control over anger and frustration [54], [55]; that they have fewer social skills [56] that they develop a learned helplessness syndrome [57], [58]; that they experience repetitive traumata [59]; that they often develop postpartum depression symptoms; and that they rate their own health as suboptimal [60].

This study aims to investigate the importance and availability of social support related to coping, resilience and mental health among unwed pregnant teenagers and teenage mothers in Malaysia during their stay in the shelter homes using mixed methods.

\section{METHOD}

\section{Sample and Procedure}

279 unmarried young pregnant women and young single mothers living in shelter homes in Kuala Lumpur and the State of Selangor participated in the quantitative part of this investigation. The respondents' age ranged from 12 to 30 years. Seventeen interviewees were selected from 
those 128 investigated unwed pregnant teenagers and teenage mothers who were 10-18 year old [61]. The inclusion criterion was that the respondents should be free from severe mental disorder and drug abuse. Four shelter homes were involved in this study; one was a governmental shelter home located in Kuala Lumpur, and the other three shelter homes were located in Selangor. All the unmarried teenagers in the participating shelter homes were asked to participate. The aims of the investigation were explained as well as the right of the participants to quit with the study at any time. Anonymity and confidentiality was assured. All of the respondents were given a questionnaire-booklet consisting of a comprehensive list of socio-demographic items, the Interview Schedule for Social Interaction [62], the Ways of Coping questionnaire [63], the Child and Youth Resilience Measure [64], and the 28-item version of the General Health Questionnaire [65] in Malay language. The respondents answered the questionnaires after giving their written informed consent. The duration of a session was approximately 45 minutes to one hour. The main author remained available throughout the sessions in order to assist when needed.

The first author's practical knowledge of the study area and the distance between shelter homes were the reasons behind choosing convenient and purposive sampling for the qualitative part of the investigation [66], [67]. Other reasons for selecting this strategy were that the respondents were institutionalized, hence they are categorized as a hard to reach population [68] and the necessary variations in the data [69].The mean age of the interviewees was $15.8 \pm 1.6$ years with a range from 12 to 18 years. Sixteen were Malays and Muslim and one was Indian and Hindu.

The one-to-one interviews lasted, on average, one hour. The main researcher introduced herself to the respondents as "kakak", which means "sister". According to the Malaysian culture, this is a common way of building rapport with the respondents and facilitating them to share their feelings and experiences freely with the researcher. Most of the interviews took place in a private room at the shelter homes, and where no private room was available; they were conducted in the garden of the respective shelter home or in the car. All these arrangements were done to ensure that the respondents felt comfortable, and that the interview proceedings remained confidential.

\section{Measurements}

Interview Schedule for Social Interaction (ISSI). Social support was assessed using the Interview Schedule for Social Interaction (ISSI). It consists of 30 items in four subscales: availability of social interaction (AVSI), adequacy of social interaction (ADSI), availability of attachment (AVAT), and adequacy of attachment (ADAT). The ISSI is a self-report measure addressing both close relationships fundamental to human development and broader social interactions important for participation in the society [70]. The reliability and validity of this scale had been tested and found acceptable in Australia [62] and in Sweden [71]. The instrument was already applied in a Malaysian study in suicide attempters and their social networks by Zainal [72]. Cronbach's alpha of the subscales ranged between 0.79 to 0.90 [73].

\section{Ways of Coping (WoC).}

The Ways of Coping questionnaire consists of 66 -items and is designed to measure various ways of coping with various stressful encounters [63]. The stressful event related to which the young mothers were supposed to respond to the WoC-items was predefined as the situation when they got to know that they are pregnant. Eight ways of coping are measured: confrontive coping; distancing; self-controlling; seeking social support; accepting responsibility; escape-avoidance; planful problem-solving; and positive reappraisal. Different results on psychometric properties in Malaysian research context have been reported with internal consistency (Cronbach's $\alpha$ ) ranged between 0.75 to 0.84 for problem-focused scale and between 0.74 to 0.87 for emotion-focused coping in an investigation on coping in university-related problems between North American, Germany and Malaysian students [74]. Abdullah, Elias, Uli and Mahyuddin [75] translated the WoC into Malay language and the content was validated by an expert-panel. This translated and adapted version of the WoC used our study was found reliable (Cronbach's $\alpha=0.87$ total, ranging from 0.54 to 0.79 for its eight subscales).

\section{Child and Youth Resilience Measure} (CYRM-28).

Resilience was measured by the Child and Youth Resilience Measure (CYRM) which consists of 28 questions related to aspects of resilience in the individual, in social relationships, culture and community. It has been tested in 14 communities in 11 countries around the world including Hong Kong and India [76]. The validity of the CYRM-28 was investigated in two Canadian samples of youth with complex needs by Liebenberg et al. [64]. Results of exploratory and confirmatory factor analyses indicated a good validity of this self-report instrument. The first two subscales, communication and individual resilience, reflect individual factors that include personal skills peer support, and social skills. The third subscale, relationships, refers to physical caregiving as well as psychological caregiving. The fourth subscale, culture, comprises contextual components that facilitate a sense of belonging in youth, components related to spirituality, culture, and education. Reliability analysis demonstrated that the CYRM-28 and its subscales are internally consistent with Cronbach's alpha ranged from .65 to .91 [64]. 
Teenage Pregnancy in Malaysia: Understanding the Importance of Social Support in Relation to Coping, Resilience and Mental Health

General Health Questionnaire GHQ -28.

General Health Questionnaire is a self-administered screening instrument psychological aspect of quality of life by 28 questions. This self-report instrument refers to somatic symptoms, anxiety and insomnia, social dysfunction and severe depression with scales General health, anxiety, depression-cognitive, and depression-behavioural. The GHQ-28 was developed for research purposes based on the original questionnaire that consists of 60 items. The questionnaire was previously validated in Malaysian culture [77]. The items were scored based on response model from 1 to 4. Cronbach's alpha coefficient for the GHQ-28 is 0.90 [78].

\section{DATA ANALYSIS}

All interviews were recorded and transcribed. The NVIVO version 9 was applied to code the meaning units in the unit of analysis using content analysis of Graneheim and Lundman [79]. Two themes have been formed in the final stage of data analysis, with ten condensed meaning units for the first theme; reactions from others. These were then categorized into seven sub-themes. Twenty-one condensed meaning-units were developed for the second theme; social situation in the shelter homes that were categorized into eight sub-themes. Mixed methods were opted for assuming that this methodological approach provides a better understanding to the investigated complex phenomenon [80].

Assuming that the frequency of talking about a topic somehow reflects its perceived importance and underlying psychological processes, we analyzed their associations with scores derived from the standardized psychological methods. Because of the small sample size frequencies and median scores were reported. Spearman Rank coefficients were calculated for testing for associations between the frequency of codes and psychological test scores. Kendall's tau-b was used for testing for differences between non-depressed and depressed participants. Since the presented findings are explorative in nature we did not correct the level of error probability for multiple testing. But, significant findings were only discussed when $\mathrm{p}<0.010$. The calculations were performed using SPSS 18.

\section{Ethical Consideration}

Formal ethical approval and administrative permission were obtained from the Economic Planning Unit, Prime Minister's Department of Malaysia, the Social Welfare Department of Malaysia and from all the shelter homes involved.

\section{RESULT}

Table 1: Reaction from others

\begin{tabular}{|c|c|c|c|c|}
\hline $\begin{array}{l}\text { Condensed } \\
\text { meaning unit }\end{array}$ & $\begin{array}{l}\mathrm{N} \\
\text { reporting } \\
\text { topic }\end{array}$ & Median & mean \pm sd & $\begin{array}{l}\text { Maximum } \\
\text { number of } \\
\text { coding }\end{array}$ \\
\hline $\begin{array}{l}\text { Pregnancy } \\
\text { was not } \\
\text { accepted by } \\
\text { family/father } \\
\text { of the fetus }\end{array}$ & 11 & 1 & $2.5 \pm 3.6$ & 14 \\
\hline $\begin{array}{l}\text { Young } \\
\text { woman not } \\
\text { accepted as a } \\
\text { person }\end{array}$ & 6 & 0 & $1.6 \pm 4.1$ & 17 \\
\hline $\begin{array}{l}\text { Forced to } \\
\text { abort by } \\
\text { father of the } \\
\text { fetus or by } \\
\text { family }\end{array}$ & 10 & 0 & $0.9 \pm 1.8$ & 7 \\
\hline $\begin{array}{l}\text { Need to hide } \\
\text { the } \\
\text { pregnancy }\end{array}$ & 8 & 0 & $1.8 \pm 4.2$ & 17 \\
\hline $\begin{array}{l}\text { Receiving } \\
\text { support from } \\
\text { significant } \\
\text { others }\end{array}$ & 4 & 0 & $0.4 \pm 0.8$ & 3 \\
\hline $\begin{array}{l}\text { Conflicting } \\
\text { feelings } \\
\text { towards the } \\
\text { fetus }\end{array}$ & 7 & 0 & $1.3 \pm 1.9$ & 6 \\
\hline $\begin{array}{l}\text { Feeling } \\
\text { detached } \\
\text { from the } \\
\text { fetus }\end{array}$ & 8 & 0 & $2.5 \pm 4.6$ & 17 \\
\hline $\begin{array}{l}\text { Pregnancy } \\
\text { was } \\
\text { perceived as } \\
\text { a financial } \\
\text { problem by } \\
\text { the family }\end{array}$ & 5 & 0 & $0.4 \pm 0.7$ & 2 \\
\hline
\end{tabular}

Twelve of the interviewees were residing in a governmental shelter home and five in a NGO's shelter home. All of them were single and four of them had already given birth. The majority considered mother, father, and siblings as their family with an average number of siblings of $4.4 \pm 1.6$ (range from 2 to 8 ). Thirteen lived together with their mothers, 10 with their fathers, and 10 also with siblings before being sent to the shelter home. Five fathers and four mothers did not agree with the accommodation of their daughter in a shelter home.

Fifteen of the young women gained an education at a secondary school and only two participated only at a primary school level. Nine of the interviewees were still students, five were unemployed, and two had already worked as unskilled waitress before coming into a shelter home. 
Frequencies of Coded Condensed Meaning Units Reactions from Others

The young pregnant women and mothers most often reported that they felt trapped owing that the solutions for their pregnancy seemed wrong and also because of being shocked of the reactions or threatened by their family or fathers of the fetus (Table 1). Nearly similar often they experienced that their pregnancy was not accepted by their significant others and they developed guilt for their bad behavior or shame. About one fourth of the interviewed teenagers mentioned that they were supported by their significant others; and their family perceived their pregnancy as a financial problem in about one third of the teenagers. About one third of the interviewed young women did, however, reported that they felt not respected as a person. But, seven of the interviewees reported that they were forced to abort by the fathers of the fetus including by physical violence. Seven of the young women developed conflicting or emotionless for the fetus or their baby.

\section{Frequencies of Coded Condensed Meaning Units - Social Situation in Shelter Homes}

The majority of the young women mentioned that they developed somewhat close relationships with a few of the other residents in the shelter homes; and that they helped each other in either by comforting their feelings or sharing household chores (Table 2). However, about one third of them told that they do not feel safe in the relationship with staff members to talk to them about their feelings or problems and more than one third did even not feel safe to talk about it with other young women in the residence. Additionally, about one third reported that they perceive a lack of family or other social support; and only about half of them said that they perceive their family as a source of strength.

But, very few indicated concerns that other residents might spread diseases within the shelter homes; that they experienced a dilemma between the relationship with the staff and relationships with the other residents; or reported that financial problems of the organization caused limitations in rules and regulations within the shelter home. Furthermore, about one third of the interviewees found they could not trust in the staff members; and about one third perceived staff members misusing their power.

However, about one third experienced the relationships with the other residents as morally rescuing; and one third reported that they could become more independent by the regulation in the shelter homes to share chores.

Coded Condensed Meaning Units for Reactions from Others Associated with Coded Condensed Meaning Units for Social Situation in the Shelter Homes

The more often the young women reported that they were forced to abort by the father of the fetus or their family, the more often they reported verbal assaults from the other residents $(\mathrm{R}=0.62 ; \mathrm{p}=0.008)$. The more often the interviewed residents reported that they developed feelings of guilt for bad behaviour or shame because of reactions of significant others towards their being pregnant, the more often the reported about a) selective close relationships with other residents $(\mathrm{R}=0.68 ; \mathrm{p}=0.003)$; $\mathrm{b})$ that they did not feel safe to talk about their feelings or problems with other residents $(\mathrm{R}=0.62 ; \mathrm{p}=0.008$; and $\mathrm{c})$ verbal assaults from other residents $(\mathrm{R}=0.66 ; \mathrm{p}=0.004)$.

\section{Associations within the Group of Condensed Meaning Units - Reactions of Others}

The more often the young pregnant women reported that their pregnancy was not accepted by their family, the more often they did not feel respected as a person $(\mathrm{R}=0.69 ; \mathrm{p}=0.002)$.

\section{Associations within the Group of Condensed Meaning} Units - Social Situation in the Shelter Homes

The more often the interviewees mentioned a few close relationships with other residents in the shelter homes, the more often they experienced the relationships with the other residents as a type of escapism $(R=0.68 ; p=0.003)$, and the more they perceived the staff in the shelter home as not trustable $(\mathrm{R}=0.63 ; \mathrm{p}=0.006)$. The more often they reported that they did not feel safe to talk about their problems and feelings to the other residents, the more often they talked about verbal assaults from other residents $(\mathrm{R}=0.79$; $\mathrm{p}<$ 0.001). The more often they experienced that the residents help each other, the more often they perceived the relationships with the other residents as morally rescuing $(R$ $=0.66 ; p=0.04)$, the more often they reported that they share household chores in the shelter homes $(\mathrm{R}=72 ; \mathrm{p}=0.001)$ and that they perceived the rules and regulations in the shelter homes as unacceptable $(\mathrm{R}=0.68 ; \mathrm{p}=0.003)$. The more often the interviewees reported that they perceived the relationships with the other residents as a type of escapism from their pregnancy issues and the reality in the home, the more often they experienced the staff there as not trustable ( $\mathrm{R}$ $=0.64 ; p=0.006)$; that the rules of the shelter homes would cause a lack of family and social support $(\mathrm{R}=0.90 ; \mathrm{p}<$ $0.001)$; and that the rules would limit the contact with their families $(\mathrm{R}=0.72 ; \mathrm{p}=0.001)$. The more often they described that the rules and regulations of the shelter homes would limit their contact with the family, the more often they evaluated that the rules would cause a general lack of social and family support $(\mathrm{R}=0.68 ; \mathrm{p}=0.003)$. And, the more often the young pregnant women evaluated the rules and regulations in the shelter homes as not acceptable, the more often they felt that they cannot talk with staff members about their feelings or problems $(\mathrm{R}=0.0 .61 ; \mathrm{p}=0.009)$ but, perceived the relationships with the other residents as morally rescuing $(\mathrm{R}$ $=0.67 ; \mathrm{p}=0.003$ ).

\section{Frequency of Condensed Meaning Units Associations with Socio-Demographic Variables}

Age was positively associated with the number of codes for that the pregnancy was to be hided $(\mathrm{R}=0.65$; $\mathrm{p}=0.005)$. Additional, the higher the household income of the family, the less often the residents reported about limited contact to their family due to rules in the shelter homes $(\mathrm{R}=-0.89 ; \mathrm{p}=$ $0.001)$.

\section{Frequency of Condensed Meaning Units and Social Support}

The more adequate the perceived attachment was evaluated (ADAT), the less often they were unclear about the rules in the shelter homes $(R=-0.68 ; p=0.003)$.

Frequency of Condensed Meaning Units and Coping

The ways of coping questionnaire was answered by the young women related to the situation when they

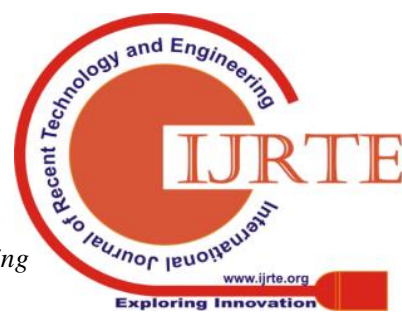


became aware of their being pregnant. The more often the interviewees reported about verbal assaults from other residents, the more often they used planful problem-solving $(\mathrm{R}=0.65 ; \mathrm{p}=0.005)$, seeking social support or acceptance of responsibility $(\mathrm{R}=0.73 ; \mathrm{p}=0.001$ or $\mathrm{R}=0.69 ; \mathrm{p}=0.002$, respectively). Attempts to avoid or to escape from the significant information was positively correlated with the frequency of mentioning that they perceived a lack of social support $(\mathrm{R}=0.63 ; \mathrm{p}=0.007)$.

Table 2: Social situation in shelter homes

\begin{tabular}{lllll}
\hline $\begin{array}{l}\text { Condensed } \\
\text { meaning unit }\end{array}$ & $\begin{array}{l}\mathrm{N} \\
\text { reporti } \\
\text { ng } \\
\text { topic }\end{array}$ & $\begin{array}{l}\text { Media } \\
\mathrm{n}\end{array}$ & $\begin{array}{l}\text { mean } \pm \mathrm{s} \\
\mathrm{d}\end{array}$ & $\begin{array}{l}\text { Maximu } \\
\text { m number } \\
\text { of coding }\end{array}$ \\
\hline Close & 13 & 1 & $2.9 \pm 4.4$ & 16
\end{tabular}

relationships

with selected

other

residents

Felt not safe

10

1

$1.2 \pm 1.7 \quad 7$

to talk about

feelings or

problems

with other

residents

Experienced

9

verbal

assaults from

other

residents

Concerns that

2

0

$0.1 \pm 0.3 \quad 1$

other

residents

spread

diseases

Relationships

7

0

$0.8 \pm 1.4 \quad 5$

with other

residents as a

type of

escapism

from the

situation

Residents

help each

other

Perceived

$$
13
$$

1

$2.2 \pm 2.6$

10

dilemma

between

friends and

stay in the

shelter homes

Relationships

5

0

$1.2 \pm 2.5 \quad 9$

with other

residents as

moral rescuer

Staff

5

5

$4.6 \pm 12.2 \quad 37$

members

misuse their

power

Felt not safe

12

1

$1.8 \pm 2.0$

their feelings

or problems

with staff

members

Staff

members

$$
8
$$

0

$1.0 \pm 2.0$

8

seen like

family

Appreciate

1

$2.1 \pm 3.0$

offered

classes in

shelter homes

Perceived

lack of family

or other

social support

caused by

regulations in

shelter homes

Contact with

family

limited

caused by

regulations in

shelter homes

Family

perceived as

source of

strength

Rules in the

11

2

$4.2 \pm 6.6$

shelter homes

in terms of

daily chore

schedules

Unclear

about rules in

the shelter

homes

Rules to share

household

chores

Rules in the

shelter homes

determined

by financial

problems

0

$0.8 \pm 1.3 \quad 5$

$1.5 \pm 2.9 \quad 12$

$5 \quad 0 \quad 1.4 \pm 2.6 \quad 8$

Frequency of Condensed Meaning Units and Resilience

The better the interviewees evaluated their communication, the less often they reported that their pregnancy was seen as a financial problem by their family $(\mathrm{R}=-0.68$; $\mathrm{p}=0.004)$. Culture related resilience aspects were significantly positively related with the frequency of reporting about verbal assaults by other residents $(R=0.69 ; p=0.003)$.

\section{Frequency of Condensed Meaning Units and Mental}

\section{Health}

The total GHQ score was significantly positive related with the frequency of reports of a lack of social support due to rules and regulations in the shelter homes $(\mathrm{R}=0.60 ; \mathrm{p}=$ 0.012).

\section{Discussion}

This study investigates relationships of social support with coping, resilience and 
mental health among unwed pregnant teenagers and teenage mothers during their residence in shelter homes in Malaysia owing their pregnancy out of wedlock. The findings are based on a mixed methods approach by combining interview data with questionnaire data of seventeen teenagers. Although the study sample was relevant to answer the research questions and provided a big variety of data, however it is important to address the limitation of the study. The cross-sectional design of the study and in addition, the sample size in this study is small and not representative.

Notwithstanding these limitations, the benefit of mixed methods was shown by strong interferences when the meaning units from the qualitative analysis were used for comparison with the scores in the questionnaires from the quantitative data [80]. The results from the previous qualitative studies with the same sample were in line with the research findings. For example, the unwed pregnant teenagers and teenager mothers experienced rejection and repression from their significant others as respond to their pregnancy. The unwed pregnant teenagers and teenage mothers also received limited contact to their family during their stay in the shelter homes. Hence by using mixed methods we could validate the findings obtained in the previous qualitative studies [81].

We found strong indication in both, the qualitative and quantitative data, that unwed teenage mothers have poor social support in terms of availability and adequacy. The negative impact of a lack of social support on mental health has been comprehensively discussed in the literature. Studies demonstrated that having poor relationships with one parents or low social support is associated with depressive symptoms, and generally can increase the risk for mental health among teenagers [82], [83]. The teenagers in this study reported about the loss of their usual social support, especially from their family, which often seemed to be caused by rules and regulations in shelter homes. The teenagers also worried and were concerned about their significant others' perspective towards themselves as well as towards their pregnancy/baby. The teenagers often mentioned that their pregnancy was not accepted; and that they have been forced to abort by their significant others. Moreover, many of them also experienced verbal assaults from other residents. Their motivational positive development such as engagement with the offered classes, perception of other residents as a moral rescuer when being advised in manners or misbehavior, and appreciation of staff members as a pseudo-family while staying in peculiar environment in a shelter home could be jeopardize without adequate social support. All the pressure may lead to feelings of unworthiness, incompetence, and loneliness and could challenge their mental health condition [83]. Lack of social support and limited contact with family in turn, might increase the risk for the teenagers to develop mental health problems such as depression.

The situation of being pregnant out of wedlock and living in a shelter home activates coping behavior in response to the many different stressful situations which unwed pregnant teenagers and teen mothers were facing. Our results indicated that unwed pregnant teenagers and teenage mothers who apply planful problem-solving, seeking social support or acceptance of responsibility when they knew that they were pregnant were also exposed to verbal assault by the other residents during their stay in the shelter home. As these teenagers suffered from poor social support in the shelter home similar to the situation when they got known that they were pregnant, their cognitive appraisal might led them to be more problem-focused in coping with their situation. However, unsupportive social network in the shelter home made them even more vulnerable to become a victim of verbal assaults. The unwed pregnant teenagers and teenage mothers used escape-avoidance coping from the significant information when they did not receive adequate social support. Avoidance coping usually gives low benefit [84] as it could divert a person's mind for possible threatening resources and failed to encourage the person to engage in appropriate problem-focused coping [85]. One of the ways of avoidance could be that the unwed teenage mothers chose not to tell others about their problems and feelings as they felt unsafe. Foa and Rothbaum [86] stated that the process of negative reinforcement; e.g. inadequacy of social support and exposure to verbal assault; can establish avoidance behaviors. Although a person who opt for avoidance owing that they may have learned to accept the reality of the stressful situation and, consequently try to minimize the risk to become distressed. But, the defense through this drawback can lead to depression or anxiety [85], [41].

The teenagers seemingly can improve their resilience by using effective ways of coping; planful problem-solving, accepting responsibility or seeking social support [84]. However, the processes of being resilient for the teenagers in this study seemed challenging because they are lacking social support as a source of resilience. One positive factor can be seen in the fact that most of the teenagers emphasized their family as a source of strength. However, the rules and regulations in the shelter homes often restricted the contact to their family. According to Marshall and Baffour [87], the young people in residential care usually perceive their family and social relations such the relationships with staff and other residents as highly important. Emond [23] stated that the young residents usually derive sense of belonging, support and advice from their fellow residents in a way that they feel unable to gain from staff members. Although the teenagers reported that they helped each other and having close relationship with selected residents and perceived the other residents as a moral rescuer but, the relationship could be more beneficial if the teenagers in this study maximize the advantage of their relationships with the other residents as their main source of social support at the time available especially to share their feelings and problems as well as to empower their resilience.

Furthermore, the teenagers also reported having few close relationships with other residents and experienced it as escapism from their current stressful life-situation in the shelter home. They possibly tried to integrate themselves by seeking companionship in the situation by creating external motivation for survival. They also may be engaged in this situation to be better socially integrated in order to be involved in the environment in the shelter home and make it meaningful for their development [87].

\section{CONCLUSION AND PRACTICAL IMPLICATIONS}

Summarizing the situation of the teenagers in the shelter homes can likely be described as very demanding and tough since they were pregnant, stayed away from family

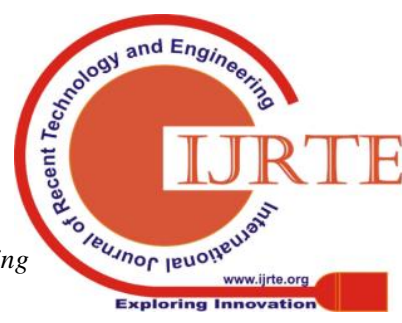


without adequate social support. The teenagers could be in the situation that Russel et al. [88] described as social loneliness. According to Russel et al. [88] lack of quantity and quality in a relationship or social network are closely related to social loneliness. According Weiss [89] social loneliness drives a person to look for engaging activities in a group he/she might participate in, whereas emotional loneliness motivates a person to seek a one-to-one intimate relationship.

In a similar vein, we found that the aspects of culture-related resilience were significantly positive associated with the frequency of reporting verbal assaults. Culture related resilience includes the aspects that are relevant to ethnic background, spiritual beliefs, religious activities, family and community traditions as well as their feelings towards their national identity. For example, young people in India evaluated prayers and religious activities as meaningful for their resilience [91]. Hence it can be concluded, the teenagers that were resilient with respect to aspects of the culture were more capable to report about verbal assault than those who were not. Those who were less resilient might have felt ashamed and had low self-esteem to talk about the verbal assault issue. The teenagers also could be afraid that the verbal assault that they were going to report will be disclosed to the person who did it and they would be even more severe or more often assaulted. The situations of the teenagers in the shelter homes causes questions how the environment in the shelter homes can be developed towards a source of empowerment for the teenagers optimistically to return to their community and the society in general.

Based on our findings, authorities and the staff in shelter homes seriously should take into account the importance of social support, especially from the usual social networks such as family, since they play a vital role for well-being and mental health of unwed pregnant teenagers and unwed teenage mothers. Furthermore, mental health problems of these teenagers are to be considered as they can lead to more serious mental health problems in the future when kept untreated.

The shelter homes could play a central role in fostering respect and help these young women to become resilient by encouraging the teenagers to build the self-confidence and social and personal skills that they need and should provide with the chance successfully to reintegrate into the community and society. This support and guidance has to be based on a deep understanding of the highly complicated situation of these teenagers before, within and after their stay in a shelter home. It is expected from shelter homes and organizations to give opportunities to the unwed pregnant teenagers and young mothers to participate in social activities, improve their social skills, moral reasoning, cognitive and vocational skills. It is also important to promote respect and openness in the communities and in the whole society by conducting community programs by politicians and local authorities assisted by social workers to enhance the understanding of these young women's needs and the phenomenon of unwed pregnancy in minors in the general public. These actions may reduce the prejudice, stigma and injustice behavior and attitudes towards them, since they usually do not actively choose to break the social and cultural norms or consciously act against their own religious beliefs.

Justify with literature support whether 128 sample size is sufficient to represent 279 population . iii. Conclusion section should contain the summary of research findings not only suggestion

\section{REFERENCES}

1. World Health Organization. (2009). Teenage pregnancies cause many health, social problems. Available: http://www.who.int/mediacentre/multimedia/podcasts/2009/teenage-p regnancy-20090213/en/index.html.

2. United Nation Children's Fund, UNICEF. (2008). Young people and family planning: Teenage pregnancy. Available: http://www.unicef.org/malaysia/Teenage_Pregnancies_-_Overview.p df.

3. R.S. Abu Bakar, M. Abdullah, \& K. Maslih, (2012, April 19), 2419 Kes seksual, rogol [2419 Cases of sexual crime, rape]. Utusan Malaysia.

Available: http://www.utusan.com.my/utusan/info.asp?y=2012\&dt=0419\&pub= utusan_malaysia\&sec $=$ Dalam_Negeri\&pg=dn_04.htm.

4. M. R. Kawi, (2011, November 3). Remaja hamil luar nikah meningkat [The increasing number of teen pregnancy out of wedlock]. Berita Harian. Available: http://www.bharian.com.my/

5. H. Kashiwase, (2002, July). Shotgun weddings a sign of the times in Japan. Population Today. Available: http://www.prb.org/Articles/2002/ShotgunWeddingsaSignoftheTimes inJapan.aspx.

6. J. G. Silverman, A. Raj, I.A. Mucci, \& J.E. Hathaway, "Dating violence against adolescent girls and associated substance use, unhealthy weight control, sexual risk behavior, pregnancy, and suicidality," Journal of the American Medical Association, 286(5), 2001, pp. 572-579.

7. M.E, Saewyc, L.L. Magee, \& E.S. Pettingell, "Teenage pregnancy and associated risk behaviours among sexually abused adolescents," Perspectives on Sexual and Reproductive Health, 36(3), 2004, pp 98-105.

8. E.T. Moffit, \& E-Risk Study Team, "Teen-aged mothers in contemporary Britain," Journal of Child Psychology and Psychiatry, 43(6), 2002, pp. 727-742.

9. S. Prawatrungruang, Understanding dropouts in Thai private vocational schools: A case study. Unpublished doctoral dissertation, Illinois State University, New York, 2002.

10. X.-K. Chen, S.W. Wen, N. Fleming, K. Demissie, G. Rhoads, \& M. Walker, "Teenage pregnancy and adverse birth outcomes: A large population based retrospective cohort study," International Journal of Epidemiology 36, 2007, pp. 368-373.

11. K. Omar, S. Hasim, N.A. Muhammad, A. Jaffar, S. M. Hashim, \& H.H Siraj, "Adolescent pregnancy outcomes and risk factors in Malaysia," International Journal Of Gynaecology And Obstetrics: The Official Organ Of The International Federation Of Gynaecology And Obstetrics, 111(3), 2010, pp. 220-223.

12. S. Thaithae, \& R. Thato, "Obstetric and perinatal outcomes of teenage pregnancies in Thailand," Journal of Pediatric and Adolescent Gynecology, 24(6), 2011, pp. 342-346.

13. N. Akiko, "Marriage for social recognition and subsequent married life," Social Science Japan, 2005, pp 6-8.

14. S. Chhabra, S. Palaparthy, \& S. Mishra, "Social issues around advanced unwanted pregnancies in rural single women," Journal of Obstetrics \& Gynecology, 29(4), 2009, pp. 333-336.

15. A. Fatimah, 2009, June, "Kes ibu tanpa nikah di Selangor berdasarkan rekod di Jabatan Kerja Sosial Perubatan, Pusat Perubatan Universiti Kebangsaan Malaysia [Unwed mother cases in State of Selangor based on the records of the Department of Medical Social Work, Hospital Universiti Kebangsaan Malaysia]," Paper presented at the Seminar Mencegah Gejala Sosial Negeri Selangor, Selangor.

16. N.A. Rahman, "Teenage Marriage in the Malay/Muslim Community of Singapore: Problems, Perceptions and Programmes," Asian Journal of Social Science, 37(5), 2009, pp. 738-756.

17. N. Sarnon, M.S. Mohamad, F. Ibrahim, K. Alavi, S. Nen, S. Hoesni, et al., "Pregnancy out of wedlock: Understanding adolescent as a basic of family intervention (Hamil luar nikah: Memahami remaja sebagai asas intervensi keluarga)," Journal of Social Sciences and Humanities, 7(1), 2012, pp. 121-130 
18. A.J. Silk, "Child abandonment and homes for unwed mothers in ancient India: Buddhist sources," Journal of the American Oriental Society, 127(3), 2007, pp. 297-314.

19. T.T. Triwulan, "Analisis hukum Islam terhadap praktik aborsi bag kehamilan tidak diharapkan (KTD) akibat perkosaan menurut Undang-undang nomor 36 Tahun 2009 tentang kesehatan [Islamic law analysis towards unwanted pregnancies abortions due to raped based on Laws Number 36 year 2009 regarding health]," Semarang: Faculty of Law Universitas Diponegero, 2009.

20. Y. Badiah, \& B. H. Mohd Jamil, “ Infanticide,” Malaysian Journal of Psychiatry, 15(2), 2006, pp. 3-10.

21. Penal Code Act 574: Incorporating all amendments up to 1 January 2006, Laws of Malaysia $§ 312$ (2006).

22. E.J. Knorth, A.T. Harder, T. Zandberg, \& A.J. Kendrick, "Under one roof: A review and selective meta-analysis on the outcomes of residential child and youth care," Children and Youth Services Review, 30, 2008, pp. 123-140.

23. R. Emond, "Putting the care into residential care: The role of young people," Journal of Social Work, 3(3), 2003, pp. 321-337.

24. V. Timonen, \& C. O'dwyer, "Living in institutional care: Residents' experiences and coping strategies," Social Work in Health Care, 48(6), 2009,pp.597-613.

25. S. Cohen, \& G. Mckay, Social support, stress and buffering hypothesis: A theoretical analysis In A. Baum, S. E. Taylor \& J. E. Singer (Eds.) Handbook of Psychological and Health. New Jersey: Hillsale, 1984.

26. J. Corcoran, C. Franklin, \& P. Bennett, "Ecological factors associated with adolescent pregnancy and parenting," Social Work Research, 24(1), 2004, pp. 29-39.

27. D. J. Martinez, \& L.S Abrams, "Informal social support among returning young offenders: A metasynthesis of the literature," International Jounal of Offender Therapy and Comparative Criminilogy, 57(2), 2013, pp. 169-190

28. M. N. Lotf Abadi, M. Ghazinour, M. Nojomi, \& J. Richter, "The Buffering Effect of Social Support between Domestic Violence and Self-Esteem in Pregnant Women in Tehran Iran," Journal of Family Violence, 27(3), 2012, pp. 225-231

29. P.A. Bovier, E. Chamot, \& T.V. Perneger, "Perceived stress, interna resources, and social support as determinants of mental health among young adults," Quality of Life Research, 13(1), 2004, pp. 161-170.

30. S. Letvak, "The importance of social support for rural mental health," Issues in Mental Health Nursing, 23, 2002, pp. 249 - 261

31. L. Theeke, R. Goins, J. Moore, \& H. Campbell, "Loneliness, depression, social support, and quality of life in older chronically ill Appalachians," Journal of Psychology, 146(1-2), 2012, pp. 155-171.

32. S. L. Johnson, A.K. Cuellar, \& C. Miller, "Bipolar and unipolar depression: A comparison of clinical phenomenology, biological vulnerability, and psychosocial predictors," In I. H. Gotlib \& C. L. Hammen (Eds.), Handbook of depression: Second edition. New York: Guilford Press, 2009

33. S. Elsenbruch, S. Benson, M. Rücke, M. Rose, J. Dudenhausen, M.K Pincus-Knackstedt et al., "Social support during pregnancy: effects on maternal depressive symptoms, smoking and pregnancy outcome," Human Reproductive, 22(3), 2007, pp. 869-877.

34. J. A. Yozwiak, "Postpartum depression and adolescent mothers: A review of assessment and treatment approaches," Journal of Pediatric Adolescent Gynecology 23, 2010, pp.172-178.

35. M. N. Loft Abadi, Social support, coping and self-esteem in relation to psychological factors: A study of health issues and birth weight in young mothers in Tehran, Iran. Umea University, Umea, 2012.

36. S. Folkman, \& R.S. Lazarus, The concept of coping. In A. Monat \& R. S. Lazarus (Eds.), Stress and coping, Columbia University Press, 1991

37. S. Folkman, \& R.S. Lazarus, Stress, appraisal and coping, New York: Springer Publishing, 1984.

38. P.A. Thoits, "Social support as coping assistance," Journal of Consulting and Clinical Psychology, 54(4), 1986, pp. 416-423.

39. S. Panzarine, "Stressors, coping, and social supports of adolescent mothers," Journal of Adolescent Health Care 7, 1986, pp. 153-161.

40. S. Panzarine, E. Slater, \& P. Sharps, "Coping, Social Support and Depressive Symptoms in Adolesecent Mothers," Journal of Adolescent Health, 17, 1995, pp. 113-119.

41. J. G. Hamilton, \& M. Lobel, "Types, patterns, and predictors of coping with stress during pregnancy: Examination of the Revised Prenatal Coping Inventory in a diverse sample," Journal of Psychosomatic Obstetrics \& Gynecology, 29(2), June 2008, pp. 97-104,.

42. S. Milan, I.R. Jeannette, T. Kershaw, J. Lewis, M. Christina, \& K. Ethier, "Prevalence, course, and predictors of emotional distress in pregnant and parenting adolescents," Journal of Consulting and Clinical Psychology, 72(2), 2004, pp. 328-340.

43. K. Tusaie, \& J. Dyer, "Resilience: A historical review of the construct," Holistic Nurse Practise, 18(1), 2004, pp. 3-8.
44. E. Werner, "Risk, resilience and recovery," Reclaiming Children and Youth, 21 (1), 2012, pp. 18-23.

45. M. Ungar, Nurturing hidden resilience in trouble youth, Toronto: University of Toronto Press, 2004

46. A.S. Masten, K.M. Best, \& N. Garmezy, "Resilience and development: Contributions from the study of children who overcome adversity," Development and Psychopathology, 2(4), 1990, pp. 425-444.

47. R. L. Woodgate, Conceptual understanding of resilience in the adolescent with cancer: Part I. Journal of Pediatric Oncology Nursing, 16(1), 1999, pp. 35-43

48. C.P. Barnard, C. P. " Resiliency: A shift in our perception," The American Journal of Family Therapy, 22, 1994, pp. 136-144.

49. M. Ungar, "Resilience across cultures," British Journal of Social Work, 38,2008 , pp. $218-235$.

50. M. Ungar, Strengths-Based Counseling with At-Risk Youth California: Corwin Press, 2006.

\section{AUTHORS PROFILE}

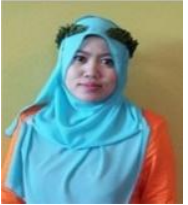

Saim, Nor Jana, PhD in Social Work. She is currently working as a senior lecturer in Social Work Program, National University of Malaysia. Her research interest particularly about teenage pregnancy and unwed mothers, as well as family studies. She is also a registered voice stress analyzer.

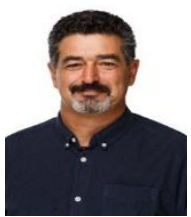

Ghazinour, Mehdi is a Professor as well as Deputy Head in Police Education Unit, Umeå University, Sweden. He participates in severa research in police science with a focus on police personality, stress, trauma and working environment.

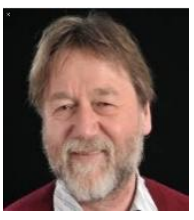

Richter, Jörg is a Professor at School of Life Sciences, University of Hull, United Kingdom. He is a clinical psychologist and licensed cognitive-behavioral psychotherapist with extensive clinical experience of working with the whole variety of psychiatric patients, in both in-and-out-patient settings as well as in both individual and group session. 